\title{
Comparação das técnicas de captura de híbridos e PCR para a detecção de HPV em amostras clínicas
}

\author{
Comparison of hybrid capture and PCR for HPV detection in clinical samples
}

Adriana Dalpicolli Rodrigues'; Vlademir Vicente Cantarelli²; Miriam Alice Frantz ${ }^{3}$; Diogo André Pilger4; Fabiana de Souza Pereira ${ }^{5}$

\begin{abstract}
unitermos resumo
HPV

Introdução e objetivos: São conhecidos mais de 100 tipos de papilomavírus humano (HPV), dos quais 30 têm sido reportados em infecções anogenitais. A infecção tem importância clínica, pois alguns tipos

PCR virais estão associados a lesões que podem progredir para o câncer cervical. Sabe-se que os métodos

PCR em tempo real moleculares são muito importantes para o diagnóstico dessa infecção. O objetivo do estudo é comparar

Captura híbrida

a detecção de HPV de alto risco pelo método de captura híbrida $2(\mathrm{CH} 2)$ com a detecção do vírus pela reação em cadeia da polimerase convencional (PCRC) e em tempo real (PCR-TR). Metodologia: Foram analisadas 56 amostras ectocervicais por $\mathrm{CH} 2$ e, após, por PCRc e PCR-TR. Resultados: Ambas, PCRc e PCR-TR, apresentaram alta concordância entre si $(95,1 \%)$, enquanto a comparação entre as PCRs e a CH2 mostrou concordância razoável entre os resultados (PCRC $=90,2 \%$ e PCR-TR = 87,8\%). Discussão e conclusão: A CH é aceita para a detecção do HPV, entretanto pode ser menos sensível em comparação com as técnicas de PCR. A PCR-TR tem a vantagem sobre a PCRc em termos de velocidade, sendo também um pouco mais sensível. Devido à alta sensibilidade e à rapidez, os métodos de PCR poderiam ser usados para a triagem de HPV em amostras ectocervicais.
\end{abstract}

\section{abstract}

Introduction and objective: More than 100 types of human papillomaviruses (HPV) are known, of which 30 have been reported in anogenital infections. The infection has clinical importance, inasmuch as some viral types are associated with lesions that can progress to cervical cancer. Molecular methods are considered an important tool for the diagnosis of this infection. The objective of this study was to compare the detection of high risk HPV using hybrid capture 2 with HPV detection by conventional and real time PCR. Methodology: 56 ectocervical samples were analyzed by hybrid capture and after that by conventional and real time PCR. Results: Both PCR and RT-PCR showed a high degree of correlation (95.1\%), whereas the comparison between $P C R$ and HC2 showed a fair correlation (90.2\% and $87.8 \%$ for $P C R$ and $R T-P C R$, respectively). Discussion and conclusions: $H C$ is widely accepted for the detection of HPV, however, it may lack sensitivity in comparison with PCR techniques. RT-PCR has further advantages over the conventional PCR in terms of speed as well as it is slightly more sensitive. Due to their high sensitivity and fast response, PCR methods could be used as a screening method for HPV detection in ectocervical samples.

1. Biomédica; mestranda em Biotecnologia pela Universidade de Caxias do Sul.

2. Ph.D. em Ciências Farmacêuticas pela Osaka University; professor da Federação de Estabelecimento de Ensino Superior em Novo Hamburgo (FEEVALE); gerente técnico do Laboratório Weinmann Ltda.

3. Doutora em Patologia pela Fundação Faculdade Federal de Ciências Médicas de Porto Alegre (FFFCMPA); professora e pesquisadora da FEEVALE.

4. Doutor em Ciências Médicas pela Faculdade de Medicina da Universidade Federal do Rio Grande do Sul (FM/UFRCS); analista clínico Sênior do Setor de Biologia Molecular do Laboratório

Weinmann Ltda.

5. Bioquímica; analista clínica do Laboratório Weinmann Ltda.

Suporte Financeiro: Laboratório Weinmann Ltda. 


\section{Introdução}

Nos dias de hoje são conhecidos mais de 100 tipos diferentes do papilomavírus humano (HPV), sendo que aproximadamente 30 possuem tropismo pelo epitélio escamoso do trato genital inferior. Os tipos virais 6, 11, 40, 42, 43, 44, 54, 61, 70, 72, 81 e CP6108 são considerados de baixo risco para o desenvolvimento de câncer cervical, sendo relacionados com lesões benignas (verrugas planas ou elevadas e neoplasia intraepitelial cervical [NIC]). Os tipos de médio e alto riscos incluem: $16,18,31,33,35,39,45$, $51,52,56,58,59,68,73$ e 82, e são relacionados a lesões de alto grau (NICs II e III) e câncer. Entre estes, os tipos 16 e 18 parecem possuir um potencial carcinogênico maior em relação aos demais vírus. Atualmente, os tipos 26, 53 e 66 também são considerados de alto risco em potencial. Além disso, muitas vezes podem ocorrer infecções por múltiplos tipos de HPV $(17,18,31)$.

A infecção persistente por tipos oncogênicos do HPV tem sido descrita como principal fator causal para o desenvolvimento do câncer do colo uterino e de suas lesões precursoras ${ }^{(29)}$. Esse tipo de câncer representa a segunda causa mais comum de câncer em mulheres no mundo, com cerca de 471 mil novos casos com 233 mil mortes reportadas a cada ano, constituindo-se em um dos mais graves problemas de saúde pública, especialmente para os países em desenvolvimento como o Brasil (cerca de 40 mil novos casos por ano) $)^{(9,23,25)}$.

A prevalência do HPV na população é alta. As estimativas globais indicam que aproximadamente $20 \%$ dos indivíduos estão infectados por algum tipo de HPV ${ }^{(10,13)}$. A expectativa é que $75 \%$ a $80 \%$ da população será infectada durante sua vida. Um aumento nesses números tem sido observado desde 1960, como consequência da prática do uso de contraceptivos orais, diminuição do uso de outros métodos de barreira, início precoce das relações sexuais, aumento do número de parceiros sexuais, paridade elevada e baixo nível socioeconômico. Além disso, avanços tecnológicos nos métodos diagnósticos nos permitiram também detectar maior número de pacientes infectados e, consequentemente, em risco para o desenvolvimento de neoplasias ${ }^{(9,21,31)}$.

O diagnóstico molecular da infecção pelo HPV é importante para a triagem do vírus e baseia-se, principalmente, em métodos como: captura híbrida $(\mathrm{CH})$, southern blot, hibridização in situ, hibridização em fase sólida (microarrays) e reação em cadeia da polimerase $(P C R)^{(28)}$. Entre eles, a captura híbrida $2(\mathrm{CH} 2)$ é o método molecular mais utili- zado em nosso meio para a detecção de HPV. Esta técnica baseia-se na hibridização de DNA, fazendo uso de sondas específicas contra os tipos de HPV considerados de alto risco ${ }^{(1,15)}$. A PCR baseia-se na amplificação específica de segmentos do DNA alvo e tem potencial para a deteç̧ão de níveis muito baixos de carga viral em células e tecidos, mesmo em infecções ditas não produtivas ${ }^{(26)}$. A PCR em tempo real (PCR-TR), por sua vez, é uma variação do método de PCR convencional (PCRC). Esta metodologia permite distinguir as sequências de bases amplificadas de DNA por análise da temperatura de separação das duplas fitas, e, como as reações ocorrem em ambiente fechado, diminui a ocorrência de contaminações. Além disso, o uso de primers universais permite, teoricamente, a detecção de todos os tipos de HPV existentes ${ }^{(6,16)}$.

Os métodos de escolha para o estudo, PCRc, PCR-TR e $\mathrm{CH} 2$, são utilizados de forma isolada para a triagem do HPV e para avaliar a eficácia da vacina contra o vírus ${ }^{(12)}$, não sendo métodos complementares para o diagnóstico da infecção. A CH2 apenas detecta os HPVs de alto risco, mas não pode determinar o tipo viral específico. Além disso, não detecta todos os tipos virais de alto risco e a sensibilidade do método (cerca de 5.000 cópias $/ \mathrm{ml}$ ) pode não ser adequada para revelar a presença do vírus no início da infecção. As técnicas que utilizam PCR são, em geral, mais sensíveis, e podem ser combinadas com a detecção por sondas específicas (linear array ou análise de polimorfismo de tamanho de fragmentos de restrição [RFLP]) para determinar os vários tipos virais ${ }^{(24)}$.

\section{Objetivo}

O objetivo principal do estudo foi comparar a detecção de HPV pelo método de $\mathrm{CH} 2$ para a pesquisa de HPV de alto risco com os resultados da PCRc e da PCR-TR em amostras ectocervicais coletadas em meio líquido para $\mathrm{CH}$ 2. Também se avaliou o uso do equipamento automatizado (Magna Pure $\mathrm{LC}^{\circledR}$, Roche) para a extração do DNA de amostras clínicas suspeitas de conterem HPV.

\section{Materiais e métodos}

Foi realizado um estudo transversal comparativo, no qual foram analisadas 56 amostras coletadas da ectocérvice de pacientes que se apresentaram no laboratório com 
requisição médica solicitando a realização do teste para a detecção do HPV no ano de 2007. As amostras foram mantidas congeladas a $20^{\circ} \mathrm{C}$ no Laboratório Weinmann de Porto Alegre (RS). Para a coleta e o transporte das amostras foram utilizados kits coletores da Digene ${ }^{\circledast}$ (Universal Collection Medium UCM).

Inicialmente utilizou-se a técnica de $\mathrm{CH} 2$ (Digene) para detecção de DNA/HPV de alto risco. A presença do HPV foi determinada por meio da quantificação da emissão de luz e expressa em unidade de luz relativa (RLU), seguindo as orientações do fabricante. As amostras com RLU < $1 \mathrm{pg} / \mathrm{ml}$ foram consideradas negativas. Os resultados com valor $\geq 1 \mathrm{pg} / \mathrm{ml}$ foram julgados positivos. Depois da utilização da técnica de $\mathrm{CH} 2$, as amostras foram congeladas $\left(20^{\circ} \mathrm{C}\right)$ para posterior análise pelos métodos de PCRc e PCR-TR.

Para a reação de $\mathrm{PCR}$, as amostras foram descongeladas e $1 \mathrm{ml}$ submetido à extração automatizada de DNA (Magna Pure LC ${ }^{\circledast}$ Roche). O kit utilizado para a extração foi o Magna Pure LC DNA Isolation Kit Large Volume, de acordo com as orientações do fabricante (Roche).

A PCRc foi realizada com o uso de tampões próprios e Platinum Taq DNA Polymerase ${ }^{\circledR}$ (Invitrogen). Os primers utilizados para a amplificação do DNA dos diversos tipos de HPV foram os universais: HPV MY11 e MY09. O produto da reação (450 pb) foi visualizado por meio da eletroforese em gel de agarose.

Para a PCR-TR foi utilizado o kit SuperScript III Platinum Two Step qRT PCR with Sybr Green, no qual foram preparados $20 \mu$ de reação para cada amostra constituída de: mistura de primers, água, DNA viral e reagentes do kit, de acordo com as orientações do fabricante. Os primers utilizados foram descritos por Payan et al. ${ }^{(26)}$.

As reações foram realizadas em capilares fechados que promovem eficaz transferência de calor, o que aumenta a eficiência da amplificação. Os resultados foram avaliados pelo aumento da fluorescência do SYBR green e análise das curvas de Melting. A reação foi processada no equipamento LightCycler, por meio da realização de 45 ciclos de amplificação de DNA $\left(95^{\circ} \mathrm{C}\right.$ para desnaturação do DNA e $60^{\circ} \mathrm{C}$ para anelamento e extensão das cadeias). Em todos os casos foram utilizados controles negativos e positivos para garantir os resultados das reações.

Todas as etapas de análise foram realizadas no Laboratório Weinmann.

A análise dos dados foi feita no programa de estatística Statistical Package for Social Sciences (SPSS), utilizando o teste de associação de kappa. Este teste mede o nível de concordância. Os valores de concordância de 0 a 0,19 são considerados "muito baixos"; de 0,21 a 0,4, "razoáveis"; de 0,41 a 0,6, "moderados"; de 0,61 a 0,8, "importantes"; e de 0,81 a 1 considera-se concordância "perfeita".

O protocolo do estudo foi aprovado pelo Comitê de Ética da Federação de Estabelecimento de Ensino Superior em Novo Hamburgo (FEEVALE), sob o número 2.01.03.07.604.

\section{Resultados}

Das 56 amostras analisadas pelas técnicas de detecção de HPV ( $\mathrm{CH} 2$, PCRc e PCR-TR), verificou-se que a $\mathrm{CH} 2$ detectou 46 amostras positivas e 10 negativas, e ambas as técnicas de PCR detectaram 41 amostras positivas e 15 negativas.

De acordo com os resultados encontrados, avaliaram-se concordância e/ou discordância entre as amostras analisadas. Entre as técnicas de $\mathrm{CH} 2$ e PCRc, há 90,2\% (37 amostras) de concordância entre as amostras identificadas como positivas e $40 \%$ (seis amostras) entre as negativas. Verificou-se discordância em $9,8 \%$ (quatro amostras) das amostras em que a $\mathrm{CH} 2$ apresentou resultado negativo enquanto o $\mathrm{PCRc}$ apresentou-se positivo, e em $60,0 \%$ (nove amostras) em que a $\mathrm{CH} 2$ apresentou-se positiva e a PCRc negativa. Demonstrouse dessa forma que há concordância razoável entre as técnicas, de acordo com o teste de associação de kappa (kappa $=0,338)$ (Tabela).

Comparando a $\mathrm{CH} 2$ com a técnica de PCR-TR, verificouse concordância em 87,8\% (36 amostras) entre as amostras positivas e $33,3 \%$ (cinco amostras) entre as negativas. Foram encontrados resultados discordantes em 12,2\% (cinco

\begin{tabular}{lcccc} 
Tabela & \multicolumn{4}{c}{ Comparação de resultados concordantes e discordantes entre as técnicas de CH e PCR } \\
\hline & PCRc positiva (\%) & PCRc negativa (\%) & PCR-TR positiva (\%) & PCR-TR negativa (\%) \\
CH2 positiva & $37(90,2)$ & $9(60)$ & $36(87,8)$ & $10(66,7)$ \\
CH2 negativa & $4(9,8)$ & $6(40)$ & $5(12,2)$ & $5(33,3)$
\end{tabular}


amostras) das amostras em que a $\mathrm{CH} 2$ apresentou-se negativa enquanto a PCR-TR apresentou-se positiva, e 66,7\% (10 amostras) em que a $\mathrm{CH} 2$ apresentou-se positiva e a PCR-TR negativa, mostrando, assim, também uma concordância razoável, segundo o teste de kappa $(\kappa=0,236)$ (Tabela).

Entre as técnicas de PCR, foram identificadas $95,1 \%$ das amostras como positivas e $86,7 \%$ como negativas, apresentando discordância em $13,3 \%$ daquelas em que a PCRc apresentou-se negativa enquanto a PCR-TR, positiva; e em 4,9\% em que a PCRc apresentou-se positiva e a PCR$\mathrm{TR}$, negativa, mostrando, de acordo com o teste de kappa $(\kappa=0,818)$, uma concordância quase perfeita.

\section{Discussão}

Muitos autores têm demonstrado alta concordância entre as técnicas de $\mathrm{CH}$ e $\mathrm{PCR}$, atingindo de 76,5\% a 90\%(3,20,22, 33). Em comparação com o método de $\mathrm{PCR}, \mathrm{a} \mathrm{CH}$ demonstra sensibilidade de $91,7 \%{ }^{(5,33)}$. Para Saini et al. ${ }^{(30)}$ a PCR foi mais sensível $(81,8 \%)$ em comparação com a CH2 $(36,4 \%)$ na detecção do HPV, embora a especificidade da $\mathrm{CH} 2$ tenha sido muito maior $(96,6 \%)$ do que a da PCR $(58,6 \%)$.

Em nosso estudo, das 56 amostras analisadas pelos métodos de $\mathrm{CH} 2$, PCR e PCR-TR para a detecção de HPV, demonstramos que as técnicas de $\mathrm{CH} 2$ e PCRc foram concordantes em 43 amostras nas quais, de acordo com o teste kappa, esta concordância é razoável. Comparando as técnicas de CH2 e PCR-TR, 41 amostras foram concordantes, apresentado também uma concordância razoável. As duas técnicas de PCR foram concordantes em 52 amostras, apresentando assim, concordância quase perfeita.

Em um estudo realizado por Nomelini et al. ${ }^{(20)}$, a $\mathrm{CH}$ apresentou $47,5 \%$ de amostras positivas para HPV de alto risco, enquanto a PCR diagnosticou $87,5 \%$ de casos positivos, mostrando fraca concordância (40\%) entre ambas $(\kappa>0,4)$. Os autores acreditam que a falha na detecção das amostras positivas pela $\mathrm{CH}$ seja devida à baixa carga viral nas amostras, tornando-as ocasionalmente falso-positivas e falso-negativas ${ }^{(2)}$. Em nosso estudo, foi a $\mathrm{CH} 2$ a técnica que detectou maior número de resultados positivos.

As amostras que apresentaram resultados positivos para $\mathrm{CH}$ e negativos para as técnicas de PCR, podem ser resultados falso-positivos da $\mathrm{CH}$, provavelmente devido a reações cruzadas com tipos de HPV não detectados pelos primers da PCR, embora não se possa afirmar. Cuzick et al.(7) demonstraram $95 \%$ de sensibilidade entre as técnicas, com
$2,3 \%$ de resultados falso-positivos pela $\mathrm{CH}$. Alguns estudos ${ }^{(4,}$ 27) têm atribuído esses resultados falso-positivos a reações cruzadas com sondas de alto e baixo riscos e necessidade de se retestarem amostras na zona cinza (próximas do cutoff de $1 \mathrm{RLU}$ ). De acordo com a padronização do teste $\mathrm{CH} 2$ pelo fabricante (Digene), as amostras com valor de RLU > 1 $\mathrm{pg} / \mathrm{ml}$ devem ser consideradas positivas. No entanto, alguns estudos demonstram que o teste teria maior especificidade se o valor de corte estivesse ao redor de $15,56 \mathrm{pg} / \mathrm{ml}$, tornando-o ideal para a deteç̧ão de lesões, diminuindo assim a possibilidade de resultados falso-positivos, principalmente em amostras com carga viral $<100 \mathrm{pg} / \mathrm{ml}$ (32).

Acreditamos, ainda, que as PCRs possam ter sido negativas por falha de amplificação (ineficiência dos primers) ou, até mesmo, por erro na extração de DNA pelo método automatizado (Magna Pure LC ${ }^{\circledR}$ ) em teste.

Em um estudo de detecção de lesões de alto grau, Nindl et al. ${ }^{(19)}$ mostraram que a $\mathrm{CH}$ apresenta falha no diagnóstico em comparação com a PCR. Kulmala et al.(11) mostraram $85 \%$ de concordância entre os dois métodos para diagnosticar as lesões. Lonky et al. ${ }^{(14)}$ demonstraram que a $\mathrm{CH}$ apresentou resultado negativo em $25 \%$ dos casos em que a PCR mostrou resultado positivo.

Nas situações em que as técnicas de PCR apresentaram resultados positivos e a $\mathrm{CH} 2$, resultados negativos, consideraram-se os resultados das PCR, pois ambas as técnicas de PCR são realizadas com primers desenhados para a detecção de HPVs de alto e baixo riscos. Em um estudo realizado por Iftner et al.(8), uma porcentagem ligeiramente maior de amostras resultou positiva na PCR-TR HPV, além de apresentar-se mais sensível e específica do que a $\mathrm{CH} 2$ seguida por um teste de HPV PCR/hibridização linha.

Em nosso estudo, comparando as duas técnicas de $P C R$, verificou-se concordância quase perfeita $(95,1 \%)$. Acredita-se que a justificativa para as amostras discordantes seja devida aos primers (MY 09/11) utilizados na PCRc, que não amplificam com a mesma eficiência os diferentes tipos de HPV. Já os primers utilizados pela PCR-TR seriam mais específicos e detectariam com maior facilidade os diferentes tipos de HPV(26). Contudo é necessário que sejam feitos mais testes para a comprovação desse fato.

\section{Conclusão}

É possível a realização da PCR em amostras coletadas nos frascos (Digene) utilizados para a coleta de amostras 
para a técnica de $\mathrm{CH} 2$, mesmo após a adição de desnaturante. Isso pode ser importante em estudos de comparação de métodos ou caso o objetivo seja utilizar PCR sem mudar o método de coleta convencional.

O equipamento Magna Pure LC ${ }^{\circledR}$ (Roche) mostrou-se eficiente para a extração de DNA, sendo melhor que o método convencional, principalmente por ser mais rápido e com menores chances de contaminação entre as amostras, porém seu custo ainda é muito alto.

As técnicas estudadas (CH2, PCRc e PCR-TR) mostraramse úteis e eficazes para o diagnóstico precoce do HPV em amostras clínicas. Entretanto, devido à técnica de $\mathrm{CH} 2$ ser mais complexa e demorada, exigindo duas reações separadas para a detecção de HPV dos tipos de alto e baixo riscos, e, ainda, por ter apresentado resultados possivelmente falso-positivos, a PCR (PCRc ou PCR-TR), principalmente por sua sensibilidade, poderia ser o método de escolha para a triagem de HPV em amostras clínicas. A PCR-TR tem a vantagem de ser mais rápida (30 min vs. 3 h) que o convencional e tem sido considerado em muitos casos mais sensível e eficiente. Contudo, os resultados positivos de qualquer uma das técnicas de PCR devem ser confirmados com outra técnica molecular, como, por exemplo, microarray ou linear array, que permitem a genotipagem para a identificação do tipo de HPV presente na amostra.

Em conclusão, todas as técnicas abordadas são importantes e adequadas para o diagnóstico do HPV e para o acompanhamento do impacto das vacinas contra HPV em ensaios clínicos. Também são necessários mais estudos comparativos para definir os custos de cada técnica na prática clínica, pois a $\mathrm{CH}$ acaba sendo mais barata que as técnicas de PCR e pode ser utilizada com mais frequência em países subdesenvolvidos ou em desenvolvimento. Enfim, é necessário que cada vez se tenha um cuidado maior na triagem do HPV, visto que a infecção por este vírus é bastante frequente na população e, se não prevenida ou tratada, pode levar a lesões sérias como câncer ou até mesmo à morte.

\section{Referências}

1. BAGARELLI, L. B.; OLIANI, A. H. Tipagem e estado físico de papilomavírus humano por hibridização in situ em lesões intra-epiteliais do colo uterino. Rev Bras Ginecol Obstet, v. 26, n. 1, p. 59-64, 2004.

2. BALERIOLA, C. et al. Comparison of a novel HPV test with the hybrid capture II (hcll) and a reference PCR method shows high specificity and positive predictive value for 13 high-risk human papillomavirus infections. J Clin Virol, v. 42, n. 1, p. 22-6, 2008.

3. BOZZETTI, M. et al. Comparison between hybrid capture II and polymerase chain reaction results among women at low risk for cervical cancer. Ann Epidemiol, v. 10, p. 466, 2000.

4. CASTLE, M. et al. Restricted cross-reactivity of hybrid capture 2 with nononcogenic human papillomavirus types. Cancer Epidemiol Biomarkers, v.11, p. 1394-9, 2002.

5. CASTLE, P. E. et al. Results of human papillomavirus DNA testing with the hybrid capture 2 essay are reproductible. J Clin Microbiol, v. 40, p. 1088-90, 2002.

6. CUBIE, H. A. et al. Rapid real time PCR to distinguish between high risk human papillomavirus types 16 and 18. Mol Pathol, v. 54, p. 24-9, 2001.

7. CUZICK, E. B. et al. HPV testing in primary screening of older women. Br J Cancer, v. 81, p. 554-8, 1999.

8. IFTNER, T. et al. Study comparing human papillomavirus (HPV) real-time multiplex PCR and Hybrid Capture II INNO-LiPA v2 HPV genotyping PCR assays. J Clin Microbiol, v. 47, n. 7, p. 2106-13, 2009.
9. INSTITUTO NACIONAL DE CÂNCER; Ministério da Saúde. Estimativa/2008: incidência de câncer no Brasil. INCA, 2007. Disponível em: <http//:www.inca.com.br>. Acesso em: 30 ago. 2009.

10. KOUTSKY, L. A.; GALOWAY, D. A.; HOLMES, K. K. Epidemiology of genital human papillomavirus infection. Epidemiol Rev, v.10, p. 122-63, 1998.

11. KULMALA, S. M. et al. Human papillomavirus testing with the hybrid capture 2 assay and PCR as screening tools. J Clin Microbiol, v. 42, p. 2470-5, 2004.

12. LEPIQUE, A. P. et al. HPV vaccination: the beginning of the end of cervical cancer? A review. Mem Inst Oswaldo Cruz, v.104, n.1, p. 1-10, 2009.

13. LINHARES, A. C. et al. Vaccines against rotavirus and human papillomavirus (HPV). J Pediatr, v. 82, p. 2534, 2006

14. LONKY, N. M. Triage of atypical squamous cells of undetermined significance with hybrid capture II: colposcopy and histologic human papillomavirus correlation. Obstet Gynecol, v. 101, p. 481-9, 2003.

15. LORINCZ, A. T. Hybrid capture method for detection of human papillomavirus DNA in clinical specimens. Papillomavirus report, v. 7, p. 1-5, 1996.

16. MOBERG, M.; GUSTAVSSON, I.; GYLLENSTEN, U. Realtime PCR-based system for simultaneous quantification of human papillomavirus types associated with high risk of cervical cancer. J Clin Microbiol, v. 25, n. 5 , p. 311-6, 2003. 
17. MOTOYAMA, S. et al. The role of human papilloma virus in the molecular biology of cervical carcinogenesis. Kobe J Med Sci, v. 50, n. 1, p. 9-19, 2004.

18. MUNÕZ, N. et al. Epidemiological classification of human papillomavirus types associated with cervical cancer. $N$ Engl J Med, v. 348, n. 6, p. 518-27, 2003.

19. NINDL, I. et al. Human papillomavirus detection in highgrade squamous intraepithelial lesions. Comparison of hybrid capture assay with a polymerase chain reaction system. Diagn Microbiol Infect Dis, v. 23, p. 161-4, 1995.

20. NOMELINI, R. S. et al. Utilization of human papillomavirus testing for cervical cancer prevention in a university hospital. Cad Saúde Pública, v. 23, n. 6, 2007.

21. NONNENMACHER, B. et al. Identificação do papilomavírus humano por biologia molecular em mulheres assintomáticas. Rev Saúde Pública, v. 36, n. 1, p. 95-100, 2002.

22. NONOGAKI S. et al. Hybrid capture II and polymerase chain reaction for identifying HPV infections in samples collected in a new collection medium: a comparison. Acta Cytol, v. 48, p. 514-20, 2004.

23. NORONHA, V. et al. Papilomavírus humano associado a lesões de cérvice uterina. Rev Soc Bras Med Trop, v. 32, n. 3, p. 235-240, 1999.

24. NOVAES, L. C. G; NOVAES, M. R. C. G.; SIMOESBARBOSA, A. Diagnosis of human papillomatosis by polymerase chain reaction in cases of divergence between results of hybrid capture and papanicolaou cytology. Braz J Infec Dis, v. 10, n. 3, p. 169-172, 2006.

25. PARKIN, D. M.; BRAY F. I.; DEVESA S.S. Cancer burden in the year 2000. The global picture. Europ J Cancer, v. 37, n. 8, p. 4-66, 2001.
26. PAYAN, C. et al. Human papillomavirus quantification in urine and cervical samples using a general realtime PCR on Mx4000 and Lightcycler systems. J Clin Microbiol, v. 45, n. 3, p. 897-901, 2007.

27. POLJAK, M. I. et al. Hybrid capture II HPV Test detects at least 15 human papillomavirus genotypes not included in its current high-risk probe cocktail. J Clin Virol, v. 25, p. 89-97, 2002.

28. RAMA, C. H. et al. Detecção sorológica de anti-HPV 16 e 18 e sua associação com os achados do Papanicolaou em adolescentes e mulheres jovens. Rev da Assoc Méd Bras, v. 52, n. 1, p.43-47, 2006.

29. ROTELI-MARTINS, C. M. et al. Associação entre idade ao início da atividade sexual e subseqüente infecção por papilomavírus humano: resultados de um programa de rastreamento brasileiro. Rev Bras Ginecol Obstet, v. 29, n.11, p. 580-587, 2007.

30. SAINI, R. et al. Evaluation of polymerase chain reaction (PCR) method and hybrid capture II (HCII) assay for the detection of human papillomavirus in cervical scrapings. Med J Malaysia, v. 62, n. 3, p. 206-9, 2007.

31. TOZETTI, I. A. et al. Multiple types of human papillomavirus in cervical samples in women in Campo Grande, MS, Brazil. Braz J Infec Dis, v. 10, n. 5, p. 309-10, 2006.

32. TULIO, S. et al. Relação entre a carga viral de HPV oncogênico determinada pelo método de captura híbrida e o diagnóstico citológico de lesões de alto grau. J Bras Patol Med Lab, v.43, n.1, p. 31-5, 2007.

33. VENTUROLLI, S. et al. Human papillomavirus DNA testing by PCR-ELISA and hybrid capture II from a single cytological specimen: concordance and correlation with cytological results. J Clin Virol, v. 25, p. 177-85, 2002. 